\title{
ChemComm
}

\section{A quick, simple, robust method to measure the acidity of ionic liquids $\dagger$}

Cite this: Chem. Commun., 2014, 50, 7258

Received 16th April 2014

Accepted 19th May 2014

DOI: $10.1039 / c 4 c c 02816 c$

www.rsc.org/chemcomm

Introduced here is a quick, simple, robust method to measure acidity in ionic liquid (IL) systems by the use of the NMR-probe mesityl oxide. Acidity corresponding to a Hammett acidity of -1 to -9 can be measured reliably using this technique, a range that vastly exceeds that of any single UV-vis probe.

Ionic liquids have become the subject of much academic attention and are being used in a range of industrial applications. ${ }^{1-3}$ The first industrial application of an ionic liquid (IL), BASF's BASIL ${ }^{\mathrm{TM}}$ process was a proton transfer reaction. ${ }^{4}$ Indeed, the most common chemical transformation in industry is the proton transfer. ${ }^{5}$ Proton transfer reactions have long been known to be solvent dependent. ${ }^{6}$ Consequently, the understanding of the effects of ionic liquids on proton transfer and acidity is vital for their widespread application.

The acidity of non-aqueous systems can be measured in many different ways, but perhaps the most well-established of these is the Hammett method which uses a range of closely related UV-vis probes to generate the Hammett acidity, $H_{0} \cdot{ }^{7-10}$ The Hammett acidity scale has been used to measure the acidity of ionic liquids ${ }^{11}$ and of solutions of acids dissolved in ionic liquids. ${ }^{12}$ However, in addition to being a timeconsuming process these measurements have proven to be problematic due to the overlapping of peaks arising from the cation of the ionic liquid and those of the probe and particularly by the presence of small amounts of impurities, including IL starting materials, by-products and process solvents including water in the ILs that can greatly affect the UV-probe due to its low concentration. Further difficulties can arise due to the often high viscosity of ILs. Attempts have been made to minimize these problems by preparing ionic liquids of unusually high purity or by measuring the acidity of solutions of ionic liquids in other

Department of Chemistry, Imperial College London, London, SW7 2AZ, UK.

E-mail: t.welton@imperial.ac.uk

$\dagger$ Electronic supplementary information (ESI) available. See DOI: 10.1039/ $\mathrm{c} 4 \mathrm{cc} 02816 \mathrm{c}$

\$ Authors contributed equally to this work. solvents. ${ }^{2}$ However, the inability to distil most ILs often makes the former approach impractical, especially since colourless solutions are required, while the latter does not provide acidity measures for the pure ionic liquids, especially in highly acidic regions (see ESI $\dagger$ ). This has contributed to a limited understanding of acidity in ILs and much of the published literature is qualified or has narrowed focus or, in some cases, the data is over interpreted (e.g. when the IL was dissolved in another solvent, see ESI $\dagger$ ). To our best knowledge the data we present here is unique in that it uses undiluted ILs and covers a wide range of acidity stretching from $-50 \mathrm{~mol} \%$ acid to $100 \mathrm{~mol} \%$ acid for the $\left[\mathrm{C}_{4} \mathrm{Him}\right]\left[\mathrm{HSO}_{4}\right]-\mathrm{H}_{2} \mathrm{SO}_{4}$ system and $0 \mathrm{~mol} \%$ acid to $100 \mathrm{~mol} \%$ acid for the $\left[\mathrm{C}_{4} \mathrm{C}_{1} \mathrm{im}\right]\left[\mathrm{HSO}_{4}\right]-\mathrm{H}_{2} \mathrm{SO}_{4}$ system.

Fărcaşiu has developed a method for measuring the acidity of a solution using the ${ }^{13} \mathrm{C}$ NMR spectrum of mesityl oxide. ${ }^{13}$ Since this probe is used in much higher concentrations than the UV-vis probes used in the Hammett methodology and the $\alpha$-carbon signal of the probe works as an internal standard, we proposed that this would lead to measurements of IL acidity being far less susceptible to the problems described above. Furthermore since the measurements are carried out using NMR rather than UV-vis spectroscopy colourless solutions are not required, further increasing the utility of the NMR-probe. The ease of Fărcaşiu's methodology gives it great potential to be useful to all chemists working with ionic liquids. In order to make use of the fact that the Hammett acidity scale is well known and understood, Fărcaşiu constructed a calibration curve for the two measurements using solutions of sulphuric acid and water, allowing for conversion of the NMR measurement into a $H_{0}$ value. However, the calibration curve was never completely investigated due to a lack of solubility of the probe in the less acidic solutions. In this paper, we use a similar methodology of comparing $H_{0}$ values to mesityl oxide $\Delta \delta$ values for a number of solutions of sulphuric acid in $\left[\mathrm{HSO}_{4}\right]^{-}$ionic liquids, extending the calibration curve to its less acidic region to reveal its full dynamic range.

Since Fărcaşiu's work measuring acidity using the mesityl oxide probe was performed on a $\mathrm{H}_{2} \mathrm{O}-\mathrm{H}_{2} \mathrm{SO}_{4}$ system $^{13}$ the 
decision was made to mimic that system as closely as possible using $\mathrm{H}_{2} \mathrm{SO}_{4}$ as the acid. Hence, two IL-acid systems where used, namely $\left[\mathrm{C}_{4} \mathrm{C}_{1} \mathrm{im}\right]\left[\mathrm{HSO}_{4}\right]-\mathrm{H}_{2} \mathrm{SO}_{4}$ and $\left[\mathrm{C}_{4} \mathrm{Him}\right]\left[\mathrm{HSO}_{4}\right]-$ $\mathrm{H}_{2} \mathrm{SO}_{4}$. Having the conjugate base $\left[\mathrm{HSO}_{4}\right]^{-}$as the $\mathrm{IL}$ anion greatly simplifies the chemical speciation in the system, because the proton transfer from the acid to the ionic liquid's anion is overall a nil reaction. $\left[\mathrm{C}_{4} \mathrm{C}_{1} \mathrm{im}\right]^{+}$and $\left[\mathrm{C}_{4} \mathrm{Him}\right]^{+}$were picked because the former is the most commonly used ionic liquid cation and the latter is the closest related protonic IL formed by direct combination of an acid and a base. These protonic ILs are relatively much easier to make in one step and they are often distillable, thereby solving two of the major problems facing the use of ILs in large scale processing today. This makes these good candidates for industrial application and potentially one of the most important types of IL for the future.

Fig. 1 shows the $H_{0}$ values for the mixtures $\left[\mathrm{C}_{4} \mathrm{C}_{1} \mathrm{im}\right]\left[\mathrm{HSO}_{4}\right]-$ $\mathrm{H}_{2} \mathrm{SO}_{4}$ and $\left[\mathrm{C}_{4} \mathrm{Him}\right]\left[\mathrm{HSO}_{4}\right]-\mathrm{H}_{2} \mathrm{SO}_{4}$. These are compared to aqueous solutions of $\mathrm{H}_{2} \mathrm{SO}_{4}$, which have been thoroughly investigated using both Hammett UV- ${ }^{8}$ and NMR-probes. ${ }^{13}$

When comparing the acidity of sulphuric acid in these ILs and water it can be seen that the same mol\% of acid will result in lower acidity in the ILs than in water. This could arise from the acid species present in the solution (see $\mathrm{ESI} \dagger$ for MS studies), but there is also a contribution from the fact that a fixed $\mathrm{mol} \%$ of acid in water has a higher acid concentration than the same mol\% in the ILs, due to the higher molar volume of the ILs. To some extent, this could also explain the increased acidity we see in $\left[\mathrm{C}_{4} \mathrm{Him}\right]\left[\mathrm{HSO}_{4}\right]$ compared to $\left[\mathrm{C}_{4} \mathrm{C}_{1} \mathrm{im}\right]\left[\mathrm{HSO}_{4}\right]$ at lower concentrations of $\mathrm{H}_{2} \mathrm{SO}_{4}$. Another possible explanation for this increase in acidity is that the presence of acidic $\mathrm{N}-\mathrm{H}$ proton on the imidazolium ring is contributing to the overall acidity of the solution. At higher concentrations of $\mathrm{H}_{2} \mathrm{SO}_{4}$, the acidities of these two IL systems are more or less indistinguishable, which would not be expected if the molar volume explanation was the main contribution (Fig. 1).

However, the most noticeable thing that can be observed from these graphs is their shapes. It is commonly known that acidity in water is not linear to the acid concentration ${ }^{8}$ due to the buffering effect of water. However, the deviation from linear behaviour for the IL-acid solutions is much less pronounced over most of the concentration range and of a different form

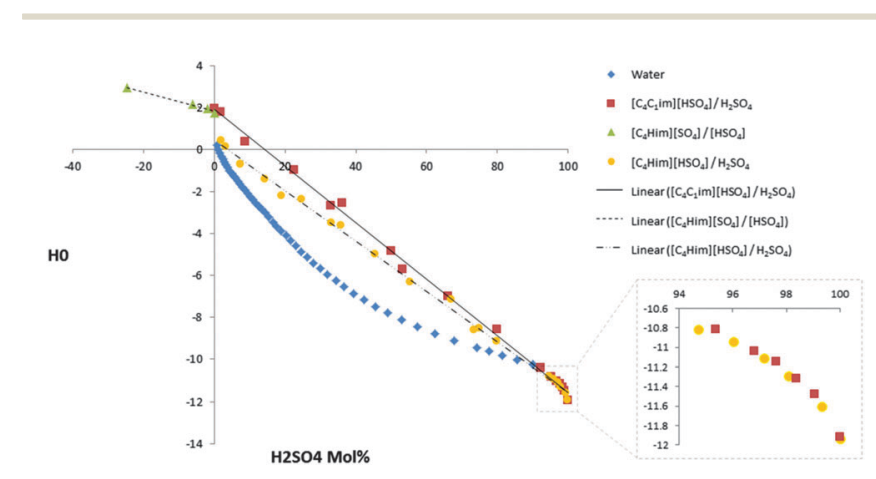

Fig. 1 The acidities of $\mathrm{H}_{2} \mathrm{O}-\mathrm{H}_{2} \mathrm{SO}_{4},{ }^{8} \quad\left[\mathrm{C}_{4} \mathrm{C}_{1}\right.$ im] $\left[\mathrm{HSO}_{4}\right]-\mathrm{H}_{2} \mathrm{SO}_{4}$, $\left[\mathrm{C}_{4} \mathrm{Him}\right]\left[\mathrm{HSO}_{4}\right]-\mathrm{H}_{2} \mathrm{SO}_{4}$ and $\left[\mathrm{C}_{4} \mathrm{Him}\right]\left[\mathrm{HSO}_{4}\right]-\mathrm{C}_{4}$ im solutions. when it does occur. This arises because the ionic liquid system is inherently simpler than the aqueous system. The anion of the ionic liquid is the conjugate base of $\mathrm{H}_{2} \mathrm{SO}_{4},\left[\mathrm{HSO}_{4}\right]^{-}$; therefore the protonation of the solvent is just the interchange of these two species to generate the same two species. This is in contrast to the aqueous solutions where $\mathrm{H}_{2} \mathrm{SO}_{4}$ will be converted into $\mathrm{H}_{3} \mathrm{O}^{+}$(and other protonated water clusters) and $\left[\mathrm{HSO}_{4}\right]^{-}$. Thus, in the ionic liquid system, under much of the concentration range of the added $\mathrm{H}_{2} \mathrm{SO}_{4}$, the only species present in the system are the ionic liquid cation, $\left[\mathrm{HSO}_{4}\right]^{-}$, solvated $\mathrm{H}_{2} \mathrm{SO}_{4}$ $\left(\left[\mathrm{H}_{3}\left(\mathrm{SO}_{4}\right)_{2}\right]^{-}\right)$and at higher concentrations of $\mathrm{H}_{2} \mathrm{SO}_{4}$, larger $\mathrm{H}_{2} \mathrm{SO}_{4}$ containing clusters (see ESI $\dagger$ for MS studies). Hence, at the lower concentrations of $\mathrm{H}_{2} \mathrm{SO}_{4}$ the only variable is the concentration of the solvated sulphuric acid species, resulting in a linear relationship between the acid concentration and the acidity of the solution. It is only at higher concentrations of $\mathrm{H}_{2} \mathrm{SO}_{4}$ that new species are generated in sufficient concentrations to affect the acidity of the solution and lead to non-linear changes in acidity with $\mathrm{H}_{2} \mathrm{SO}_{4}$ concentration (Fig. 1). The formation of these anionic clusters have recently been observed using ${ }^{1} \mathrm{H}$-NMR and IR spectroscopy ${ }^{14}$ and is further supported by our own MS study (see ESI $\dagger$ ).

For $\left[\mathrm{C}_{4} \mathrm{Him}\right]\left[\mathrm{HSO}_{4}\right]-\mathrm{H}_{2} \mathrm{SO}_{4}$ deviation from linear behaviour is also seen at the other extreme when an excess of 1-butylimidazole is added. Comparison of the $\mathrm{p} K_{\mathrm{a}} \mathrm{s}$ of the species suggests that this system is better described as $\left[\mathrm{C}_{4} \mathrm{Him}\right]_{1+x}\left[\mathrm{SO}_{4}\right]_{x}\left[\mathrm{HSO}_{4}\right]$, rather than $\mathrm{C}_{4} \mathrm{im}\left[\mathrm{C}_{4} \mathrm{Him}\right]\left[\mathrm{HSO}_{4}\right]$. Additionally, it can also be noted that as this $\left[\mathrm{C}_{4} \mathrm{Him}\right]_{1+x}\left[\mathrm{SO}_{4}\right]_{x}\left[\mathrm{HSO}_{4}\right]$ description changes to $\left[\mathrm{C}_{4} \mathrm{Him}\right]\left[\mathrm{HSO}_{4}\right] \mathrm{H}_{2} \mathrm{SO}_{4}$ the slope of the graph increases. This is because $\mathrm{H}_{2} \mathrm{SO}_{4}$ is more acidic than $\left[\mathrm{HSO}_{4}\right]^{-}$so an equal molar increase of the corresponding acid in both systems will result in higher increase in acidity for the $\left[\mathrm{C}_{4} \mathrm{Him}\right]\left[\mathrm{HSO}_{4}\right] \mathrm{H}_{2} \mathrm{SO}_{4}$ solutions than for $\left[\mathrm{C}_{4} \mathrm{Him}\right]_{1+x}\left[\mathrm{SO}_{4}\right]_{x}\left[\mathrm{HSO}_{4}\right]$.

To assess the dynamic range of the mesityl oxide methodology the acidities of a range of $\left[\mathrm{C}_{4} \mathrm{Him}\right]\left[\mathrm{HSO}_{4}\right]-\mathrm{H}_{2} \mathrm{SO}_{4}(50 \mathrm{~mol} \%$ 1-butylimidazole to $\left.100 \mathrm{~mol} \% \mathrm{H}_{2} \mathrm{SO}_{4}\right)$ solutions were assessed by measuring the difference $(\Delta \delta \mathrm{ppm})$ between the ${ }^{13} \mathrm{C}$ NMR signals of the $\alpha$ and $\beta$ carbons of mesityl oxide (Fig. 2). For protocol see the ESI. $\dagger$

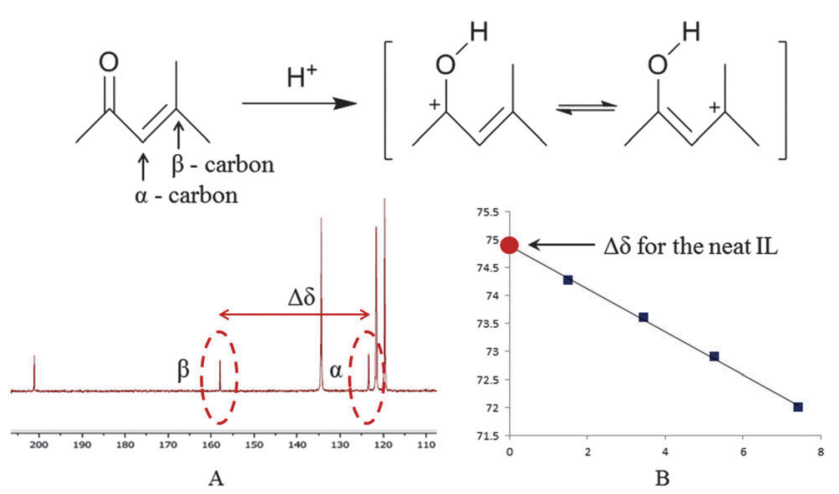

Fig. $2 \Delta \delta$-value was collected at four different mesityl oxide concentrations (A). The $\Delta \delta$-value for the neat IL, that is no mesityl oxide present, was then extrapolated from this data (B). 


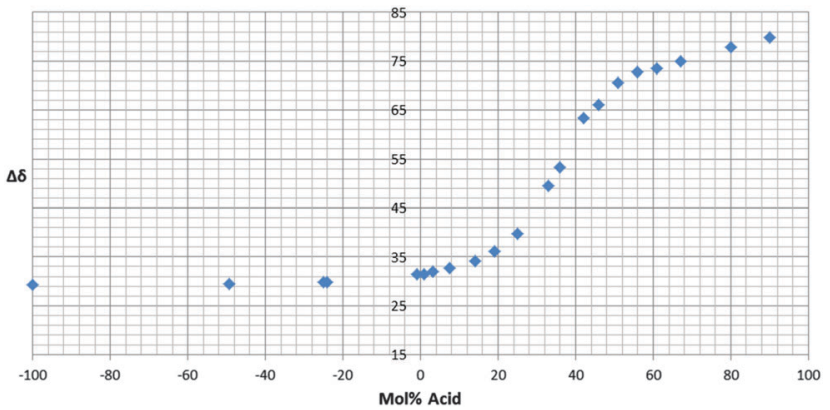

Fig. $3 \Delta \delta$ vs. $\mathrm{mol} \% \mathrm{H}_{2} \mathrm{SO}_{4}$. Negative values of mol\% acid indicates an excess of 1-butylimidazole as such $-100 \mathrm{~mol} \%$ acid equals $\left[\mathrm{C}_{4} \mathrm{Him}\right]_{2}\left[\mathrm{SO}_{4}\right]$. The spectra of some of the more viscous ILs (excess 1-butylimidazole) were recorded at $80{ }^{\circ} \mathrm{C}$, with only a marginal decrease in the $\Delta \delta$ value (for $\left[\mathrm{C}_{4} \mathrm{Him}\right]\left[\mathrm{HSO}_{4}\right] \Delta \delta$ decreased by $0.98 \mathrm{ppm}$ on heating from room temperature to $80^{\circ} \mathrm{C}$ ).

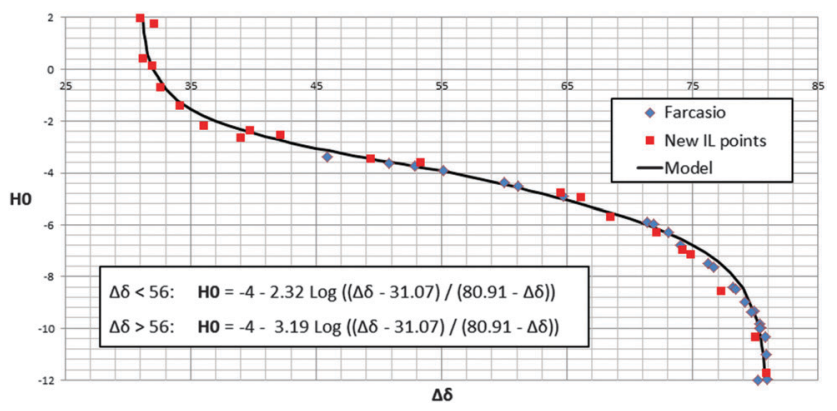

Fig. $4 \Delta \delta$ vs. $\mathrm{H}_{0}$ for $\left[\mathrm{C}_{4} \mathrm{Him}\right]\left[\mathrm{HSO}_{4}\right]-\mathrm{H}_{2} \mathrm{SO}_{4},\left[\mathrm{C}_{4} \mathrm{C}_{1} \mathrm{im}\right]\left[\mathrm{HSO}_{4}\right]-\mathrm{H}_{2} \mathrm{SO}_{4}$ and $\mathrm{H}_{2} \mathrm{O}-\mathrm{H}_{2} \mathrm{SO}_{4}^{13}$ (see $\mathrm{ESI} \uparrow$ for details of model).

The form of the titration curve plotted in Fig. 3 is dependent upon the probe's sensitivity to changes in acidity in the different acidity ranges. The precision of any acidity measurement based upon measurements of $\Delta \delta$ is determined by the slope of the line at any given acid concentration. For $\left[\mathrm{C}_{4} \mathrm{Him}\right]\left[\mathrm{HSO}_{4}\right]-\mathrm{H}_{2} \mathrm{SO}_{4}$ this gives a range between $15-50 \mathrm{~mol} \%$ $\mathrm{H}_{2} \mathrm{SO}_{4}$ within which good precision can be achieved. Beyond this range to higher acidities, the measurement is possible, but the lower slope of the curve leads to noticeably lower precision, whilst at low acid concentrations the line becomes almost flat $(\Delta \delta$ for 1-butylimidazole $=28.82 \mathrm{ppm}$, not included in the graph) and no meaningful measurement can be made.

Having measured the acidity of various $\mathrm{IL}-\mathrm{H}_{2} \mathrm{SO}_{4}$ solutions using both $\Delta \delta$ of mesityl oxide and $H_{0}$ it is now possible to calibrate the former against the latter. This was previously been done by Fărcaşiu for $\mathrm{H}_{2} \mathrm{O}-\mathrm{H}_{2} \mathrm{SO}_{4} \cdot{ }^{13}$ Fig. 4 shows the data for that system and also the data collected from both of our IL systems. As can be seen the data from the two $\mathrm{IL}-\mathrm{H}_{2} \mathrm{SO}_{4}$ systems show excellent agreement with the data for the $\mathrm{H}_{2} \mathrm{O}-$ $\mathrm{H}_{2} \mathrm{SO}_{4}{ }^{13}$ in the range that these overlap. This is expected since the identities of the solvent and acid have no effect upon this comparison, only the acidity of the solutions. The measurements of the acidity of the $\mathrm{H}_{2} \mathrm{O}-\mathrm{H}_{2} \mathrm{SO}_{4}$ system cover a smaller acidity range, because at low $\mathrm{H}_{2} \mathrm{SO}_{4}$ concentrations the mesityl oxide is insufficiently soluble to give a NMR signal. However, the ILs-acid systems have no such limitations; on the contrary mesityl oxide can be dissolved at very low acid concentrations or even under basic conditions, thereby increasing the scope of mesityl oxide as an acidity probe past the point previously reported. ${ }^{13}$ We can now see the full range of the utility of the $\Delta \delta$ of mesityl oxide acidity measurements that covers the range of $H_{0}$ values from approximately -1 to -9 .

Outside the range $H_{0}=-1$ to -9 , large changes in $H_{0}$ correspond to small changes in $\Delta \delta$, hence the precision of the conversion is poor. This does raise the question of whether it is better to use the $\Delta \delta$ measurement directly as the acidity measurement rather than converting to $H_{0}$. While it is true that using $\Delta \delta$ directly avoids the problems associated with compounding the errors of two different measurement methods, converting to $H_{0}$ does have the advantage that $H_{0}$ is a well understood measurement.

A model derived from the Hammett equation was also fitted to the data in Fig. 4 with some adjustments for separate hydrogen bond donation and acceptance effects. It was observed that there is a stronger mitigation of the effects of protonation on the NMR spectrum of mesityl oxide in the more acidic region below a $H_{0}$ of -4 , which could derive from a hydrogen bond acceptance effect from the anion, compared to the less acidic regions compositions where we would expect a hydrogen bond donation effect towards mesityl oxide to dominate. (For further details see ESI. $\dagger$ )

To summarise, $\Delta \delta$ mesityl oxide offers an easy, quick and robust single probe based system for the measurement of the acidities of IL-acid solutions in the range of $H_{0}=-1$ to -9 . The use of NMR removes the need for a colourless ionic liquid, which is often a problem for the Hammett UV-vis based methodology. The high concentration of mesityl oxide used in these measurements reduces the sensitivity of the measurement to small traces of impurities in the ionic liquid. That the technique relies on a single probe saves time in identifying which probe to use. However, the sheer number of Hammett probes available does mean that one of these can usually be identified to give very precise acidity values once the approximate acidity of the solution being measured is known. The advantage of the system described here is that it will allow many more measurements of the acidity of ionic liquids and their acid solutions than have been possible to date. We will continue to do this in order to elucidate the behaviour of acids in ionic liquids.

\section{Notes and references}

1 P. Wasserscheid and T. Welton, Ionic liquids in synthesis, Wiley-VCH, Weinheim, 2003.

2 J. P. Hallett and T. Welton, Chem. Rev., 2011, 111, 3508-3576.

3 N. V Plechkova and K. R. Seddon, Chem. Soc. Rev., 2008, 37, 123-150.

4 M. Maase, K. Massonne and K. Halbritter, US Pat., WO 2003062171 , 2008.

$5 \mathrm{~K}$. Weissermel and H.-J. Arpe, Industrial organic chemistry, $\mathrm{VCH}$, Weinheim, New York, 3rd comple., 1997.

6 C. Reichardt and T. Welton, Solvents and solvent effects in organic chemistry, Wiley-VCH, Weinheim, Germany, 4th updat., 2011. 
7 L. P. Hammett and A. J. Deyrup, J. Am. Chem. Soc., 1932, 54, 2721-2739.

8 P. Tickle, A. G. Briggs and J. M. Wilson, J. Chem. Soc. B, 1970, 65-70. 9 R. j. Gillespi, T. E. Peel and E. A. Robinson, J. Am. Chem. Soc., 1971, 93, 5083-5087.

10 T. Q. To, Investigation of the acidity and nucleophilicity of ionic liquid mixtures and their effects on reaction rates, Imperial College London, 2012.
11 H. B. Xing, T. Wang, Z. H. Zhou and Y. Y. Dai, J. Mol. Catal. A: Chem., 2007, 264, 53-59.

12 C. Thornazeau, H. Olivier-Bourbigou, L. Magna, S. Luts and B. Gilbert, J. Am. Chem. Soc., 2003, 125, 5264-5265.

13 D. Fărcaşiu and A. Ghenciu, Prog. Nucl. Magn. Reson. Spectrosc., 1996, 29, 129-168.

14 K. Matuszek, A. Chrobok, F. Coleman, K. R. Seddon and M. Swadźba-Kwaśny, Green Chem, 2014, DOI: 10.1039/C4GC00415A. 